\title{
DA REGULARIZAÇÃO FUNDIÁRIA DAS OCUPAÇÕES IRREGULARES DO SOLO URBANO E A CONCRETIZAÇÃO DO DIREITO SOCIAL À MORADIA
}

\author{
Maiara Sanches M. Rocha ${ }^{1}$ \\ Ricardo dos Reis Silveira ${ }^{2}$
}

\begin{abstract}
RESUMO: A política pública de regularização fundiária dos loteamentos clandestinos e o parcelamento irregular do solo ensejam a criação de favelas nos territórios urbanos. A finalidade é demonstrar que com a regularização tornar-se-á possível a transformação dos locais de ocupações irregulares em legítimos loteamentos, dotados de infra-estrutura básica, garantindo a moradia digna e respeito os direitos sociais do indivíduo. A partir de um estudo bibliográfico e documental, utilizando-se da metodologia descritiva e dedutiva. A busca é uma solução para ao menos minimizar os problemas resultantes das irregularidades das ocupações pelas populações de baixa renda.
\end{abstract}

Palavras- Chave: Regularização fundiária; Política Pública; Direito Social.

\section{THE ENVIRONMENTAL REGULARIZATION OF IRREGULAR OCCUPATIONS ON URBAN GROUND AND THE CONCRETIZATION OF SOCIAL LAW TO HOME}

\begin{abstract}
This paper aims to provide for the regularization of public policy of illegal settlements and when the irregular land subdivision, which entails the creation of slums in urban areas. The purpose is to demonstrate that with the adjustment shall become possible the transformation of places of illegal occupation of legitimate settlements, provided with basic infrastructure, ensuring decent housing and respect the social rights of the individual. From a bibliographical and documentary study, using descriptive and deductive methodology. The theme is current and very relevant for dealing with a social right of the individual and the development of urban centers, social phenomena to be observed, analyzed and solved by the Government. We are looking fora solution to at least minimize the problems resulting from irregularities occupations by low-income populations.
\end{abstract}

Keyword: Land Regularization; Public policy; Social rights.

\footnotetext{
${ }^{1}$ Registradora de Imóveis, Mestranda em Direito - Proteção e Tutela dos Direitos Coletivos- pela Universidade de Ribeirão Preto/SP. Doutoranda na área de ciência jurídica na Pontificia Universidade Católica da ArgentinaPUC.

${ }^{2}$ Professor titular do programa de pós graduação da UNAERP. Mestre e doutor em filosofia e metodologia das ciências pela UFSCAR.
}

Rev. de Direito Urbanístico, Cidade e Alteridade | e-ISSN: 2525-989X | Maranhão | v. 3 | n. 2 | p. 72 - 87 | Jul/Dez. 2017. 


\section{INTRODUÇÃO}

A população brasileira concentra-se no solo urbano visando o aumento da qualidade de vida migram das zonas rurais ou de pequenas cidades para os grandes e médios centros. Diante do crescimento urbano demasiado as cidades não conseguiram acompanhar por meio de planejamento essas mudanças.

Para o oferecimento de infra-estrutura em uma cidade se faz necessária a oferta de alguns equipamentos e serviços, tais como água, esgoto, transporte, saúde. Com o crescimento descontrolado e de maneira rápida da urbe há a ocupação de zonas de forma irregular, subnormal.

Para que os territórios urbanos não cresçam de forma irregular e desordenada utiliza-se de um instituto jurídico denominado de parcelamento do solo, o qual vem para construir e moldar a urbanização.

Entretanto, por muitas vezes a lei não é obedecida, criando os loteamentos clandestinos, irregulares ou mesmo o parcelamento irregular do solo urbano, não estando contidos nos planejamentos urbanísticos e com infra-estrutura escassa.

A ocupação irregular do solo urbano traz consigo adversidades que refletem nas demais áreas de prestação de serviço de uma cidade, posto que a saúde, o saneamento, o meio ambiente são influenciados pelos danos decorrentes da falta de planejamento, nada obstante trazem contaminação aos recursos hídricos e induzem a disseminação de doenças.

O problema de pesquisa do presente trabalho é demonstrar que a não regularização fundiária das ocupações de solo irregulares nas cidades afronta as normas específicas a respeito do tema e causa prejuízos a toda a sociedade. Portanto, cabe demonstrar que a regularização fundiária se torna a política pública aplicável ao caso para a transformação de locais e terras irregulares em regulares, oferecendo ao indivíduo uma melhor qualidade de vida posto que moradia e dignidade da pessoa humana estão intimamente ligados.

O objetivo principal do presente trabalho é demonstrar as situações causadas pela ocupação irregular dos solos urbanos e suas consequências. Mister informar que as irregularidades decorrentes deste tipo de ocupação afetam a população em um todo, posto que ao não oferecer uma infra-estrutura básica, tal como esgoto, saneamento, todos os outros bairros e territórios entorno estarão prejudicadas pela falta de prestação dos serviços, mesmo que a eles sejam oferecidos.

Rev. de Direito Urbanístico, Cidade e Alteridade | e-ISSN: 2525-989X | Maranhão | v. 3 | n. 2 | p. 72 - 87 | Jul/Dez. 2017. 
No que tange o objetivo específico é a busca da solução para implementação das políticas públicas de regularização e a manutenção destas em todo o território urbano uma vez que de nada adiantará regularizar apenas uma parte das terras irregulares sem que se vise o futuro e garanta a infra-estrutura para todos os locais necessitados. Ademais, trata-se de um problema social, deve-se fornecer moradia digna e estabelecer diretrizes e cuidados para que a população de baixa renda possa vir a se estabelecer e manter o que fora regularizado.

O problema trazido no presente trabalho é social, não basta o investimento em políticas públicas, na regularização fundiária ou mesmo atribuir a problemática as famílias se baixa renda se o Poder Público não buscar e implementar um conjunto de medidas que visam a oferecer moradia digna a população e evitar o surgimento de novas ocupações irregulares.

\title{
2. DO DIREITO A PROPRIEDADE
}

O tema direito da propriedade é aprofundado por muitos estudiosos posto que se trata de um direito subjetivo complexo, o qual expõe pensamentos, teses e teorias de diversos doutrinadores quanto ao assunto, sendo de tamanha importância ao indivíduo.

De acordo com Friederich Engels (1964, p. 127) as reformas e revoluções ocorridas nas sociedades todas foram voltadas e relacionadas à propriedade.

\begin{abstract}
Até hoje, todas as revoluções têm sido contra um tipo de propriedade e em favor de outro; um tipo de propriedade não pode ser protegido sem que se lese outro. Na grande Revolução Francesa, a propriedade feudal foi sacrificada para que se salvasse a propriedade burguesa; na revolução de Sólon, a propriedade dos credores sofreu em proveito da dos devedores: as dívidas foram simplesmente declaradas nulas. Ignoramos os pormenores, mas Sólon se gaba, em seus poemas, de ter feito arrancar aos campos hipotecados as marcas de dívida e de ter propiciado o repatriamento dos homens que, endividados, foram vendidos como escravos ou fugiram para o estrangeiro. Isso não podia ser feito senão por uma flagrante violação dos direitos de propriedade. E, na realidade, desde a primeira até a última dessas chamadas revoluções políticas, todas elas se fizeram em defesa da propriedade, de um tipo de propriedade, e se realizaram por meio do confisco dos gens (dito de outro modo: do roubo) por outro tipo de propriedade.
\end{abstract}

Para tratarmos a respeito do tema do presente estudo devemos discorrer brevemente a respeito do modo de aquisição de terras no Brasil no início dos tempos, tratando ainda a respeito da posse e propriedade. Passa-se então, a conceituação dos institutos e a explicação de seu desenvolvimento no decorrer da história. 


\subsection{Da aquisição das terras no Brasil}

Primeiramente, para entendermos o presente estudo deve-se buscar o histórico do direito de propriedade em nosso ordenamento pátrio. Para Saule Júnior (2006, p. 16) Portugal instituíra no Brasil o sistema de sesmarias ${ }^{3}$, o qual concedia o domínio de terras a pessoas desde que estas as tornassem produtivas.

A problemática começa a surgir diante da ocupação de terras devolutas por posseiros, ou seja, as terras pertencentes ao domínio público, que por este foram inutilizadas, ou sequer destinadas a qualquer outro fim (MEIRELLES, 1993, p. 455) uma vez que não apresentavam qualidade para produção ou o acesso à terra era dificultoso, árduo foram dominadas por pessoas que não possuíam o título de propriedade.

No ano de 1850 houve a edição da Lei n 601 no Brasil, denominada Lei das Terras de 1850. Nos ensinamentos de Martins (1997, p. 17) a lei veio com o intuito de tornar árduo o acesso à propriedade por trabalhadores, posto que duas semanas antes de sua promulgação o Brasil proibira o tráfico de escravos, sendo assim, escassa a mão de obra, deveriam os trabalhadores laborar em grandes fazendas e não adquirir a propriedade. Ademais, a lei permitia a aquisição de terras somente pelo meio da compra e venda, porém elevara os preços, dificultando assim o acesso ao título.

É mister que a Lei de Terras tinha como objetivo principal inalterar a estrutura agrária do país e solucionar a problemática quanto a mão de obra para as lavouras de café. Dispõe Martins (1997, p. 17-18) a respeito:

O objetivo era criar "por meios falsos" uma massa real e verdadeira de "despossuídos" [...], que não tivesse nenhuma outra alternativa senão trabalhar para os grandes proprietários de terra. A Lei de Terras foi um artifício para criar um problema e, ao mesmo tempo, uma solução social em benefício exclusivo dos que tinham e têm terra e poder.

Neste ponto há que ressaltar que não havia um regime livre de aquisição de terras no país. No ano de 1854 , houve a promulgação do decreto $\mathrm{n}^{\circ} 1.318$, o qual passou a expor que a regularização das posses seriam feitas por vigários das paróquias, os quais eram assinadas de próprio punha e em duas vias, sendo entregues ao padre da paróquia, porém as demarcações das terras não eram exatas e os domínios baseavam-se em marcos instáveis (REYDON et. Al, 2006, p. 56).

\footnotetext{
${ }^{3} \mathrm{O}$ sistema sesmarias fora um sistema de distribuição e ocupação de terras concebido no território brasileiro abrangendo o período da "descoberta" até o ano de 1822.
}

Rev. de Direito Urbanístico, Cidade e Alteridade | e-ISSN: 2525-989X | Maranhão | v. 3 | n. 2 | p. 72 - 87 | Jul/Dez. 2017. 
Em 24 de setembro de 1864, fora criada a instituição do registro de imóveis por meio da Lei $\mathrm{n}^{\mathrm{o}}$ 1.237, impondo assim a necessidade de registrar em cartório tanto a posse quanto a propriedade do imóvel para que se fosse averiguado o caráter de legalidade.

A Constituição da República de 1891 preservou o princípio da aquisição da propriedade por meio da compra, porém passou a admitir o instituto do usucapião a alguns posseiros (GOMES et. al., 2014, p. 312).

Com o advento do Código Civil de 1916 fora reafirmada a obrigatoriedade do registro dos títulos em cartórios extrajudiciais para a real aquisição da propriedade e normatizou o usucapião em terras públicas (GUEDES; REYDON, 2012).

Ademais, o Código Civil de 1916, trouxe além do conceito de propriedade, os direitos os quais o proprietário estava resguardado, ou seja, trazia em seu artigo 524 o direito ao proprietário de "usar, gozar e dispor de seus bens, e de reavê-lo do poder de quem quer que injustamente o possua".

Posteriormente, nos moldes da Constituição Federal de 1988, em razão da função social da propriedade, o Código Civil de 2002 deixa de lado o caráter individualista, o qual se encontrava tão presente no Código anterior. Assim, presume-se a propriedade plena e exclusiva, até prova em contrário, nos moldes do artigo 1.231, Código Civil de 2002.

\subsection{Do Conceito de Posse e Propriedade}

Importante tecer a respeito da propriedade e da posse posto que se tratam de instituto diferentes e estão envolvidos nos temas a serem tratados no presente trabalho: moradia e ocupação de loteamentos clandestinos.

Primeiramente cabe ressaltar que o instituto da propriedade está contido dentro dos direitos reais, sendo o mais complexo dentro os existentes (artigo 1.225, Código Civil). Ambos os institutos encontram respaldo legal e são protegidos pela Constituição Federal e suas normas disciplinadas no Código Civil.

Posse e propriedade estão intimamente ligadas, relacionando-se pelo fato de que a posse "é o ato que permite e possibilita o exercício do direito de propriedade" (ALVIM, 1987, p. 47). A teoria objetiva de Ihering conceitua posse como "uma situação de fato, em que uma pessoa, independentemente de ser ou não proprietária, exerce sobre uma coisa poderes ostensivos, conservando-a e defendendo-a" (PEREIRA, 2002, p. 14).

Rev. de Direito Urbanístico, Cidade e Alteridade | e-ISSN: 2525-989X | Maranhão | v. 3 | n. 2 | p. 72 - 87| Jul/Dez. 2017. 
No que tange a propriedade Venosa (2007, p. 57) a trata como direito amplo entre a pessoa e a coisa, há a presença do dominus. Deste modo, pode-se dizer que "o domínio é o direito real que vincula e legalmente submete ao poder absoluto de nossa vontade a coisa corpórea" (GOMES apud LAFAYETE, 2002, p. 98). Ademais, os direitos reais são caracterizados pelo direito de sequela, ou seja, poderá o proprietário reaver o bem de quem quer o detenha.

A propriedade é o mais amplo dos direitos reais, abrangendo a coisa em todos os seus aspectos. É o direito perpétuo de usar, gozar e dispor de determinado bem, excluindo todos os terceiros de qualquer ingerência neste. Essa plenitude do direito de propriedade distingue o dos outros direitos reais, denominados direitos reais limitados. (WALD, 2002, p. 104)

Por se tratar de um dos direitos mais complexos, cabe as palavras do ilustre jurista

Orlando Gomes:

A propriedade é um direito complexo, se bem que unitário, consistindo num feixe de
direitos consubstanciados nas faculdades de usar, gozar, dispor e reivindicar a coisa
que lhe serve de objeto.
Direito absoluto também é porque confere ao titular o poder de decidir se deve usar a
coisa, abandona-la, aliená-la, destruí-la, e, ainda, se lhe convém limitá-lo,
constituindo, por desmembramento, outros direitos reais em favor de terceiros. Em
outro sentido, diz-se, igual mente, que é absoluto, porque oponível a todos. Mas a
oponibilidade erga omnes não é peculiar ao direito de propriedade. O que lhe é próprio
é esse poder jurídico de dominação da coisa, que fica ileso em sua
substancialidade ainda sofre certas limitações.
Por último, seu caráter de direito absoluto se manifesta mais nitidamente no aspecto
real de poder direto sobre a coisa com o qual se distingue das outras relações jurídicas.
O direito de propriedade é perpétuo. Incluindo a perpetuidade entre seus caracteres,
significa-se que tem duração ilimitada, e não se extingue pelo não-uso. (GOMES,
2001, p. 97)

Visando somente uma explanação a respeito dos conceitos de ambos os institutos posto que o presente trabalho não visa esgotá-los passa-se então a discorrer a respeito da urbanização ocorrida de forma irregular.

\section{DO PARCELAMENTO DO SOLO}

O processo de urbanização da população brasileira vem acelerando demasiadamente nas últimas décadas, ensejando em uma ocupação desmazelada do solo, dando surgimento a favelas e a um mercado informal de habitações e moradias, ocorrendo o parcelamento do solo de forma irregular e ilegal.

Rev. de Direito Urbanístico, Cidade e Alteridade | e-ISSN: 2525-989X | Maranhão | v. 3 | n. 2 | p. 72 - 87 | Jul/Dez. 2017. 
De acordo com José Carlos de Freitas (2000) o "crescimento urbano veio desacompanhado de um planejamento que pudesse absorver as necessidades de oferta de equipamentos urbanos (água, luz, esgoto, etc.) e de serviços públicos de transporte, educação e saúde pública”.

O parcelamento do solo consiste em um instituto utilizado para organizar o território municipal buscando infra-estrutura urbanística básica, promovendo uma adequada distribuição de lotes, vias públicas, sistema viário, definindo assim o território urbano.

Realizado sob a forma de desmembramento, loteamento ou desdobro o parcelamento do solo trata-se de um dos instrumentos urbanísticos utilizados para organização territorial dos municípios brasileiros (MOTA, 1980).

O crescimento adequado de uma cidade depende do parcelamento do solo, posto que por meio deste serão definidas as características e confrontações dos territórios municipais, de seus equipamentos comunitários, urbanos, dos sistemas de abastecimento, recreação, entre outros, propiciando assim qualidade de vida a todos os indivíduos que habitem naquele perímetro.

Harmônico seria o crescimento das cidades se as normativas condizentes ao parcelamento do solo fossem respeitadas. Conforme já exposto, encontra-se em grande parte dos territórios urbanos assentamento irregulares, loteamentos clandestinos, ambientes estes que não respeitam as normas municipais, estaduais, federais e principalmente os preceitos ambientais.

As normas que regulamentam o parcelamento do solo urbano em âmbito nacional estão contidas na Lei Federal 6.766 de 19 de dezembro de 1979, norteando assim as normas estaduais e municipais.

A lei de parcelamento do solo (Lei 6.766/79) especifica na inteligência de seu artigo $2^{\circ}$, que o aquele poderá ser realizado de duas maneiras, por meio de loteamento ou desmembramento.

\footnotetext{
O parcelamento urbanístico visa à formação de lotes vocacionados à edificação para moradia, lazer, comércio, indústria ou para fins institucionais, dotados de equipamentos urbanos (redes de água, esgoto, sistema de captação e drenagem das águas pluviais, energia domiciliar, iluminação pública, telefonia, etc.) e comunitários (áreas de lazer e recreio, educação e cultura, saúde, etc.). (FREITAS, 2000)
}

Uma vez que haja a subdivisão de gleba em lotes, destinado a edificação, com abertura de novas vias, prolongamento, ampliação ou modificação das existentes, considerarse-á loteamento, assim dispõe a inteligência do artigo $2^{\circ}, \S 1^{\circ}$, da lei supracitada. 
Diferentemente será o desmembramento, mesmo se tratando da subdivisão de uma gleba, não haverá a abertura de novas vias ou logradouros públicos uma vez que este não encontra-se presente no tema abordado no presente trabalho não iremos aprofundar seu estudo.

dispõe ainda a lei de parcelamento do solo que o loteamento poderá ser realizado quando observadas as disposições legais e as legislações estaduais e municipais pertinentes. Observadas as especificações legais, aprovado o projeto de loteamento, o loteador deverá registrá-lo na respectiva serventia de Registro de Imóveis dentro do prazo de 180 dias, sob pena de caducidade da aprovação.

Ressalta-se ainda que trata-se de uma obrigação do loteador a realização das obras de infraestrutura básica do loteamento, atendendo os índices urbanísticos trazidos pelo plano diretor.

\subsection{Do loteamento clandestino, irregular e do parcelamento irregular do solo (assentamentos coletivos)}

Visto que o loteamento é um modo de parcelamento do solo, passaremos a tratar a respeito das diferenças entre o loteamento clandestino e o irregular.

O território brasileiro em sua maior parte está constituído por meio de parcelamento irregular do solo. Estes são empreendimentos realizados em desrespeito a legislação urbanística, a Lei de Parcelamento do Solo, as normas registrais, entre outros.

Ressalta-se que tais empreendimentos irregulares por muitas vezes são vendidos sem qualquer documentação que comprove sua regularidade ou mesmo a venda, posto que não respeitam os planejamentos urbanísticos e não oferecem infra-estrutura a população.

Tais loteamentos são adquiridos por pessoas de baixa renda, muitas das quais desconhecem as normas do processo de realização e estruturação de um lote. Por desconhecerem das normas alguns acreditam ser proprietários dos terrenos os quais habitam, porém sem a regularidade urbanística não há como se falar em regularidade de venda, posto que é obrigatório o registro do loteamento nos Registros de Imóveis competentes, e para tanto a norma deve ser obedecida.

É mister que uma vez não registrado o loteamento, é como se o mesmo não tivesse existência jurídica, consequentemente, não pode ser objeto de alienação. O que temos nesses casos é uma ocupação irregular do solo urbano.

Rev. de Direito Urbanístico, Cidade e Alteridade | e-ISSN: 2525-989X | Maranhão | v. 3 | n. 2 | p. 72 - 87 | Jul/Dez. 2017. 
Um dos meios de ocupação irregular do solo urbano é o loteamento irregular o qual obedecera a algumas das normas do parcelamento urbano, possuindo assim algum tipo de registro no Município, porém posteriormente deixo de obedecer algum ato necessário a sua regularização. Um exemplo seria a apresentação do projeto de loteamento, sua aprovação posterior pelo órgão competente, porém a falta de registro dentro do prazo de 180 dias, conforme artigo 18, Lei 6.766/79.

Quanto ao loteamento clandestino, a situação é mais grave, pois não houve sequer qualquer registro ou aprovação pela prefeitura, ou seja, não houve qualquer intervenção pública. Neste caso há um total desrespeito às normas urbanísticas, denominando-se assim a clandestinidade do lote. Portanto, são projetos que não aprovados pela autoridade competente, argumenta FREITAS (2000, p. 335) neste sentido:

Clandestino não é, apenas, o loteamento feito às ocultas. Tanto é aquele desconhecido
oficialmente pelo Poder Público, porque inexistente solicitação de aprovação, quanto
o que deriva do indeferimento do respectivo pedido, por não atender às exigências
legais. Num e noutro caso, sempre sem a chancela oficial, ele é implantado
fisicamente pelo loteador, com a abertura de ruas, demarcação de quadras e lotes e
com a edificação de casas pelos adquirentes.

Por fim, temos o parcelamento irregular do solo. Este ocorre mediante a criação de assentamentos informais diretamente por pessoas de baixa renda, podemos denomina-los de favelas. Não há a compra de um lote, mas sim a construção em um terreno que não fora devidamente parcelado. No presente caso não há a realização de um compra e venda e sim toma-se posse de um terreno e nele constrói a habitação.

\section{DA POLÍTICA PÚBLICA DE REGULARIZAÇÃO FUNDIÁRIA}

Observa-se que para famílias carentes as grandes cidades são vistas como lugares com demasiada oferta de oportunidades para um crescimento profissional, moradia e melhores condições de vida para o indivíduo e sua família.

Ocorre que esta não é a realidade enfrentada, por muitas vezes pessoas migram do interior de seus estados em busca de oportunidades nas capitais, ou em cidades com uma maior infra- estrutura, porém acabam não encontrando o que desejam.

Devido a uma grande parcela de solo urbano desocupadas e a falta de moradia, de um local para habitação de alguns indivíduos, dá-se ensejo a ocupação irregular das terras. 
Acontece que tal problemática não é vista apenas nas grandes cidades, posto que o desemprego e a falta de condições a sustento digno acarretam a ocupação, surgindo assim problemas não somente urbanísticos, mas também, jurídico, social e econômico.

Ante a ausência de uma alternativa habitacional para a população de menor renda, abrangendo não somente as grandes cidades, mas também cidades de interiores, principalmente no decorrer das duas últimas décadas, a consequência que se destaca é a ocupação irregular e inadequada ao meio ambiente urbano (MARTINS, 2002, 16).

Aprovada na data de 10 de julho do ano de 2001, a Lei 10.257, denominada de Estatuto da Cidade, estabeleceu diretrizes gerais da política urbana, oferecendo instrumentos para intervenção no mercado de terras, objetivando o cumprimento da função social da propriedade.

Importante instrumento oferecido pela lei 10.257/2001 foi a previsão normativa da regularização fundiária. Especifica o artigo $2^{\circ}$, inciso XIV, do Estatuto da Cidade o seguinte:

Art. 2ㅇ A política urbana tem por objetivo ordenar o pleno desenvolvimento das funções sociais da cidade e da propriedade urbana, mediante as seguintes diretrizes gerais:

$[\ldots]$

XIV - regularização fundiária e urbanização de áreas ocupadas por população de baixa renda mediante o estabelecimento de normas especiais de urbanização, uso e ocupação do solo e edificação, consideradas a situação socioeconômica da população e as normas ambientais;

Passamos então a análise do instituto da regularização fundiária, o qual encontrava seu conceito exposto no artigo 46 da Lei 11.977 de 07 de julho de 2009, consistindo em:

Art. 46. (...) conjunto de medidas jurídicas, urbanísticas, ambientais e sociais que visam à regularização de assentamentos irregulares e à titulação de seus ocupantes, de modo a garantir o direito social à moradia, o pleno desenvolvimento das funções sociais da propriedade urbana e o direito ao meio ambiente ecologicamente equilibrado.

Neste sentido tem-se que a regularização fundiária pode ser compreendida como um processo social-jurídico-econômica, o qual trará transformações com o objetivo de prosperar assim o direito social à habitação, regulamentando e legalizando a permanência de indivíduos em áreas urbanas ocupadas em desacordo com a legislação pátria.

Com o advento da MP 759/2016, a qual passou a regulamentar as questões decorrentes da regularização fundiária rural e urbana e com sua transformação em lei (13.465/2017), aprovada no Senado Federal na data de 31 de maio de 2017, houve revogação de algumas das regras constantes na lei 11.977/2009.

Rev. de Direito Urbanístico, Cidade e Alteridade | e-ISSN: 2525-989X | Maranhão | v. 3 | n. 2 | p. 72 - 87 | Jul/Dez. 2017. 
As novas regras trazidas pela lei 13.465/2017, a respeito da regularização fundiária buscam regulamentar as áreas urbanas e rurais, públicas ou privadas, que foram formadas em desacordos com as normas as quais conduzem o assunto. Há que ressaltar que várias são as formas de irregularidades, tendo como exemplos as favelas, cortiços, loteamentos irregulares, clandestinos, dentre outras formas.

O principal objetivo do instituto é regularizar essas áreas, a ocupação do solo, para que se tornem legítimas as posses, cumprindo assim um dos princípios constitucionais mais importantes, ou seja, cumprindo a função social da propriedade e garantindo ao indivíduo o direito a uma moradia digna.

No que tange aos programas de regularização fundiária importante frisar que "os programas de regularização devem objetivar a integração dos assentamentos informais ao conjunto da cidade, e não apenas o reconhecimento da segurança individual da posse para os ocupantes (FERNANDES, 2002, p. 15). Neste sentido temos que a regularização fundiária não visa somente regularizar a posse dos indivíduos, mas sim, urbanizar a cidade, garantindo a todos o direito social a moradia e a implementação de uma infra- estrutura urbana.

Portanto, conforme a Lei Federal $n^{\circ} 11.977 / 09$, a regularização fundiária é um conjunto de medidas jurídicas, urbanísticas, ambientais e sociais, com o objetivo de regular os assentamentos irregulares à titulação de seus ocupantes, em acordo com a função social da propriedade e o direito constitucional a habitação.

\section{DO DIREITO SOCIAL À MORADIA}

O direito à moradia encontra amparo na Constituição Brasileira e por normas e instrumentos internacionais, é uma pretensão dos membros da coletividade perante o Estado, componentes das Constituições democráticas modernas e da legislação positiva dos Estados contemporâneos. Todavia, um direito positivado não significa um direito efetivo e concreto, por vezes se faz necessária a ação positiva do Estado por meio de execução de políticas públicas para que este encontre eficácia.

A moradia é um direito fundamental inerente a pessoa humana, reconhecido expressamente na ordem jurídica brasileira. Consagrado na declaração Universal dos Direitos Humanos da ONU de 1948, temos em seu artigo XXV:

[...] todos têm direito ao repouso e ao lazer, bem como a um padrão de vida capaz de assegurar a si e a sua família saúde e bem estar, inclusive alimentação, vestuário,

Rev. de Direito Urbanístico, Cidade e Alteridade | e-ISSN: 2525-989X | Maranhão | v. 3 | n. 2 | p. 72 - 87 | Jul/Dez. 2017. 
habitação, cuidados médicos, e serviços sociais indispensáveis, o direito à segurança em caso de desemprego, doença, invalidez, viuvez, velhice, ou outros casos de perda dos meios de subsistência em circunstâncias fora de seu controle.

Saule Júnior (1997, p. 66) afirma que por se tratar os direitos humanos de direitos universais, indivisíveis, interdependentes e inter-relacionados, a alimentação, vestuário, habitação são componentes constantes de um padrão de vida adequado, digno, pelo qual a pessoa somente terá um padrão de vida adequado se foram assegurados e respeitados esses direitos

No ordenamento pátrio o direito à moradia fora incluído no rol de direitos sociais por advento da Emenda Constitucional n ${ }^{\circ} 26$ de 14 de fevereiro do ano de 2.000:

Art. $1^{\circ} . \mathrm{O}$ art. $6^{\circ}$ da Constituição Federal passa a vigorar com a seguinte redação:

"Art. $6^{\circ}$. São direitos sociais a educação, a saúde, o trabalho, a moradia, o lazer, a segurança, a previdência social, a proteção à maternidade e à infância, a assistência aos desamparados, na forma desta Constituição.

Art. $2^{\circ}$. Esta Emenda Constitucional entra em vigor na data da sua publicação.

Brasília, 14 de fevereiro de 2000.

Viana (2.000, p. 9) caracteriza o direito à moradia como tendo sido designado a expressão mínima do próprio direito à vida. Entretanto, como dito anteriormente, o direito positivado por vezes não encontra concretude se não houver uma ação do Estado na aplicação de políticas públicas, neste caso as habitacionais, incluindo a regularização fundiária.

$\mathrm{O}$ direito a uma moradia digna inclui entre seus elementos uma infra-estrutura básica, condições de moradia adequada, serviços que oferecem um bem-estar ao indivíduo, posto que a dignidade da pessoa humana é um dos pilares de nosso ordenamento.

[...] habitação digna ou adequada é aquela que oferece condições de vida sadia, com segurança, apresentando infraestrutura básica, como suprimento de água, saneamento básico e energia, e contando com a prestação eficiente de serviços públicos urbanos, tais como saúde, educação, transporte coletivo, coleta de lixo. Ainda, pressupõe a segurança da habitação: é possível ir e vir em segurança e o local não é suscetível a desastres naturais. Quanto à acessibilidade, é preciso que a infraestrutura viária permita o acesso decente e seguro à habitação.

De acordo com a definição legal de moradia digna, caso haja omissão do poder público, cabe ao Poder Judiciário o controle judicial de omissões administrativas na área de saneamento ambiental. Com efeito, essas omissões atingem diretamente a dignidade humana e infringem, por consequência, os deveres constitucionais impostos a todos os entes federativos de defender e preservar o meio ambiente e de realizar ações para promover a saúde pública (CF, art. $225 \mathrm{c} / \mathrm{c}$ art. 196) (HABITAT apud DIAS, 2010, p. 69).

O artigo 23, inciso IX, da Constituição Federal de 1988 dispõe que é de competência de todos os entes federados "promover programas de construção de moradias e a melhora das condições habitacionais e de saneamento básico". 
Ademais, é de competência do município, por intermédio da política urbana, "ordenar o pleno desenvolvimento das funções sociais da cidade e da propriedade urbana" garantindo o "direito a cidades sustentáveis, entendido como o direito à terra urbana, à moradia, saneamento ambiental, infra-estrutura urbana" entre os demais itens constantes no inciso I, do artigo $2^{\circ}$ do Estatuto da Cidade (Lei 10.257/2001).

Demonstrado que o direito à moradia é um direito social e elencado como direitos humanos, de caráter universal, é dever do Estado buscar a execução das políticas públicas de regularização fundiária de ocupações irregulares do solo urbano, fornecendo aos indivíduos uma moradia digna, amparada por infra-estrutura básica e bem-estar psíquico, social e físico, garantindo assim a concretização do instituto.

\section{CONCLUSÃO}

A irregularidade urbana é um problema grave encontrado não somente em grandes centros urbanos, mas em cidades em desenvolvimento, caracterizando-se como um fenômeno social que a afeta todos os habitantes daquele território urbanístico.

A posse e propriedade, apesar de serem institutos diferentes, abrangidos por áreas diversas do direito civil, estão interligados posto que são direito dos quais o indivíduo possui sobre determinado bem. Quando presentes, àquela é assegurado o direito a uma moradia digna e em se tratando apenas de posse, há a possibilidade de preenchendo os requisitos legais vir a ser tornar o efetivo proprietário do bem, podendo usar, dispor, gozar, usufruir e exercer o direito de sequela frente ao bem.

É mister que no Brasil o acesso a propriedade fora tornado árduo desde os tempos mais remotos, posto que a coroa portuguesa visava a imigração de Europeus para que estes adquirissem terras no Brasil, enquanto a população que aqui habitava deveria trabalhar nos grandes feudos uma vez que não havia mais mão de obra em decorrência da proibição do tráfico de escravos.

O parcelamento do solo é um instituo jurídico utilizado para definir o tecido urbano, servindo suas normativas para regularização o solo e o espaço constante dos territórios, visando a organização e a formação de infra-estruturas que atendam a população local. Realizado por meio do loteamento ou desmembramento, deve respeitar as normativas constantes na Lei 
6.766/79 para ser caracterizado como loteamento regular, atendendo assim, o que fora disposto no texto normativo e oferecendo aos habitantes o mínimo necessário.

Há que ressaltar que muitos loteamentos não são criados de acordo com as normas legais, passando a ser caracterizados como irregulares ou clandestinos, não garantindo dignamente a estrutura necessária aos habitantes, posto que estes que lá habitam são indivíduos de baixa renda.

Não apresentando infra-estrutura básica, estando em desacordo com as normas jurídicas brasileiras, causando uma desorganização no solo urbano, caberá ao Estado intervir e por intermédio de políticas públicas de regularização e estabelecer uma organização, para que o crescimento urbano se desenvolva de maneira eficaz, dentro dos padrões necessários definidos pela lei 6.766/79 e oferecer aos habitantes o respeito ao princípio da dignidade da pessoa humana ao trazer a eles uma habitação digna.

A regularização dos loteamentos clandestinos visa a população que ali habita o acesso amplo à moradia, por meio de uma gestão do solo urbano, da criação de uma infraestrutura básica, conforme requisitos legais, oferecendo assim uma moradia digna e de qualidade a uma população de baixa renda.

Importante ainda, se faz a regulamentação e realização dos programas de regularização fundiária dos loteamentos clandestinos objetivando assim, a integração dos assentamentos irregulares ao território urbanístico, reconhecendo a posse e propriedade dos habitantes e garantindo o direito à habitação, previsto na Constituição Federal de 1988, e tratado como direito social inerente a todo ser humano.

Por fim, o processo de regularização é o instrumento para adequar os loteamentos clandestino às normas legais, assegurando o direito à moradia e ao desenvolvimento urbano, reconhecendo ainda o direito de posse e propriedade daqueles que lá habitam e por consequência, acautelar a formação de novos assentamentos clandestinos e os impactos trazidos ao ambiente urbano.

Rev. de Direito Urbanístico, Cidade e Alteridade | e-ISSN: 2525-989X | Maranhão | v. 3 | n. 2 | p. 72 - 87 | Jul/Dez. 2017. 


\section{REFERÊNCIAS}

ALVIM, J. M. de A. Breves Anotações para uma Teoria Geral dos Direitos Reais, in Posse e Propriedade. Coord. Yussef Said Cahali, São Paulo, Saraiva, 1987.

DIAS, D. S. O direito à moradia digna e a eficácia dos direitos fundamentais sociais. In: Revista do Ministério Público do Pará. Pará: Liceu, ano V, vol. I, dez, 2010.

ENGELS, F. A Origem da Família, Propriedade Privada e do Estado. Rio de Janeiro: Civilização Brasileira, 11. ed., 1987.

FREITAS, J. C. de. Loteamentos clandestinos: uma proposta de prevenção e repressão. Ministério Público de São Paulo. Disponível em: $<$ http://imobiliaria.mastergeoengenharia.com.br/imagens/editor/files/loteamentosclandestinosjose-carlos-de-freitas.pdf > Acesso em 15 set. 2016.

GUEDES, S. N. R.; REYDON, B. P. Direitos de propriedade da terra rural no Brasil: uma proposta institucionalista para ampliar a governança fundiária. Revista de Economia e Sociologia Rural, 2012. Disponível em: <http://www.scielo.br/scielo.php?pid=S010320032012000300008\&script=sci_arttext\&tlng=es>. Acesso em: 13 ago. 2016.

GOMES, C. M. P. et. al. Governança da terra e (re) territorialização da agricultura familiar: possibilidades do crédito fundiário no Brasil. Revista Campo- território: revista de geografia agrária, v. 9, n. 19, p. 308-336, 2014.

GOMES, Orlando. Direitos Reais. Atualização e notas de Humberto Theodoro Júnior. Rio de Janeiro: Impetus, 18 ed., 2001.

MARTINS, José de Souza. A questão agrária e o papel do MST. In: STÉDILE, João Pedro (org.) A reforma agrária e a luta do MST. Petrópolis: Vozes, 1997.

MEIRELLES, H. L. Direito administrativo brasileiro. São Paulo: Malheiros, 18 ed. atualizada, 1993.

PEREIRA, Caio Mário da Silva. Instituições de Direito Civil: Parte geral. Rio de Janeiro: Forense, 19 ed. 2002.

REYDON, B. P. et al.Regulação da propriedade rural no Brasil: resultados dos primeiros passos. In: REYDON, B. P.; CORNÉLIO, F. N. M. Mercados de terras no Brasil: estrutura e dinâmica. Brasília: NEAD (Nead Debate; 7), 2006.

SAULE JUNIOR, N. et al. Manual de regularização fundiária em terras da União. Instituto Polis: São Paulo, Brasília: Ministério do Planejamento, Orçamento e Gestao. 2006, p. 120. Disponível $\mathrm{em}:$ <http://www.planejamento.gov.br/secretarias/upload/arquivo/spu/publicacoes/081021_pub_m anual_regularizacao-1.pdf/view>. Acesso em 08 set. 2016. 
VENOSA, Sílvio de Salvo. Direitos reais. São Paulo: Atlas, 3. ed., 2002.

VIANA, Rui Geraldo Camargo. O Direito à Moradia. Revista de Direito Privado, abr/jun 2000.

WALD, Arnoldo. Direito das Coisas. São Paulo: Saraiva, 11. ed., 2002. 